Document downloaded from:

http://hdl.handle.net/10251/81914

This paper must be cited as:

Khramtsova, E.; Sosnovsky, D.; Ageeva, A.; Nuin Plá, NE.; Marín García, ML.; Purtov, P.; Borisevich, S.... (2016). Impact of chirality on the photoinduced charge transfer in linked systems containing naproxen enantiomers. Physical Chemistry Chemical Physics. 18(18):12733-12741. doi:10.1039/C5CP07305G.

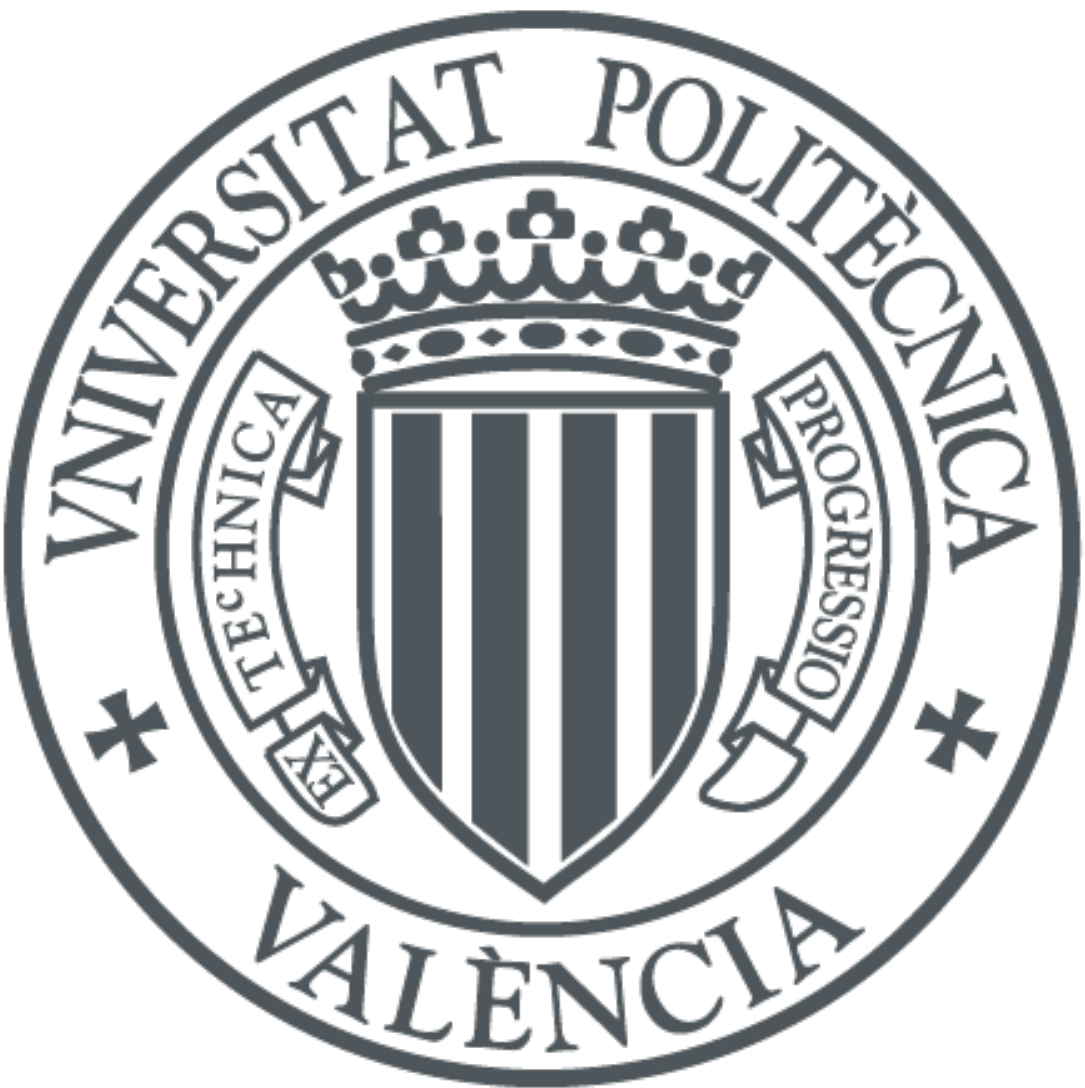

The final publication is available at

http://doi.org/10.1039/c5cp07305g

Copyright Royal Society of Chemistry

Additional Information 


\section{Impact of chirality on the photoinduced charge transfer in linked systems containing naproxen enantiomerst}

E. A. Khramtsova ${ }^{\text {ab }}$, D. V. Sosnovsky ${ }^{\text {ab }}$, A. A. Ageeva ${ }^{\text {ab }}$, E. Nuin ${ }^{c}$, M. L. Marin ${ }^{c}$, P. A. Purtov ${ }^{\text {ab }}$, S. S. Borisevich ${ }^{\text {d }}$, S. L. Khursan ${ }^{\text {d }}$, H. D. Roth ${ }^{\text {e }}$, M. A. Miranda ${ }^{\text {c }}$, V. F. Plyusnin ${ }^{a b}$ and T. V. Leshina ${ }^{a}$

${ }^{a}$ Institute of Chemical Kinetics and Combustion SB RAS, Institutskaya st., 3, 630090

Novosibirsk, Russia. E-mail: khramtsovaea@gmail.com

${ }^{b}$ Novosibirsk State University, Pirogova st., 2, 630090 Novosibirsk, Russia

'Departamento de Química/Instituto de Tecnología Química UPV-CSIC, Universitat

Politècnica de València, Camino de Vera s/n, 46022 Valencia, Spain

${ }^{\mathrm{d} U f a}$ Institute of Chemistry RAS, Prospect Octyabrya st., 71, 450054 Ufa, Russia

eDept. Chem. \& Chem. Biol., Rutgers State University, Piscataway, NJ 08854, USA

Received 26th November 2015, Accepted 4th April 2016

First published on 11th April 2016

The model reaction of photoinduced donor-acceptor interaction in linked systems (dyads) has been used to study the comparative reactivity of a well-known antiinflammatory drug, (S)-naproxen (NPX) and its (R)-isomer. (R)- or (S)-NPX in these dyads is linked to (S)-N-methylpyrrolidine (Pyr) using a linear or cyclic amino acid bridge (AA or CyAA), to give (R)-/(S)-NPX-AA-(S)-Pyr flexible and (R)-/(S)-NPXCyAA-(S)-Pyr rigid dyads. The donor-acceptor interaction is reminiscent of the binding (partial charge transfer, CT) and electron transfer (ET) processes involved in the extensively studied inhibition of the cyclooxygenase enzymes (COXs) by the NPX enantiomers. Besides that, both optical isomers undergo oxidative metabolism by enzymes from the $\mathrm{P} 450$ family, which also includes ET. The scheme proposed for the excitation quenching of the (R)- and (S)-NPX excited state in these dyads is based on the joint analysis of the chemically induced dynamic nuclear polarization (CIDNP) and fluorescence data. The ${ }^{1} \mathrm{H}$ CIDNP effects in this system appear in the back electron transfer in the biradical-zwitterion (BZ), which is formed via dyad photoirradiation. The rate constants of individual steps in the proposed scheme and the fluorescence quantum yields of the local excited (LE) states and exciplexes show stereoselectivity. It depends on the bridge's length, structure and solvent polarity. The CIDNP effects (experimental and calculated) also demonstrate stereodifferentiation. The exciplex quantum yields and the rates of formation are larger for the dyads containing (R)-NPX, which let us suggest a higher contribution from the CT processes with the (R)-optical isomer.

\section{Introduction}


The difference in activity of drug chiral isomers is currently in scientific focus. $\frac{1-4}{} \mathrm{~A}$ good example is the class of non-steroidal anti-inflammatory drugs (NSAIDs), since, despite a great variety of chemical structures of NSAIDs, many of them demonstrate different therapeutic activity exactly between optical isomers..$^{5}$

The basic activity of NSAIDs is the inhibition of the cyclooxygenase enzymes (COXs) which perform the oxygenation of arachidonic acid, a precursor of several prostaglandins, potentiating an activity of inflammatory mediators. In recent years NSAID analgesic ${ }^{7}$ and anti-cancer ${ }^{-}$activity has also drawn attention. For that, their analgesic effect is associated with the inhibition of endocannabinoid (natural analgesic agents) oxidation by COX $2 .^{7}$ Furthermore, it has been recently observed that the CoA esters of NSAIDs are the substrates of another enzyme, $\alpha$-methylacyl CoA racemase (AMACR). $\underline{8}$ AMACR levels and activity are associated with certain types of cancer (prostate, colon and others). ${ }^{-}$Today the chiral inversion of optically active NSAIDs by AMACR is considered as a novel mechanism of their anti-cancer activity; it is believed that the enzymatically activated conversion of NSAIDs blocks the other harmful effects of an entire group of enzymes (transferases).$\frac{810-15}{1 t}$ is worth emphasizing that this activity of NSAIDs also shows high stereoselectivity..$^{11,12,14}$

The stereoselectivity of NSAIDs in biological chemistry is investigated, specifically

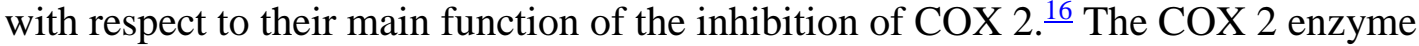
has several active sites: one catalytic site provides cyclization, and another one performs oxidation (involving electron transfer (ET)).

Of special interest now is one representative of NSAIDs, naproxen (NPX, 6-methoxy- $\alpha$ methyl-2-naphthaleneacetic acid), because only the (S)-isomer has anti-inflammatory activity, $\underline{-17}$ and it is actually sold as an enantiopure drug. Only the (S)-isomer inhibits prostaglandin's synthesis, however, both the (R)- and (S)-optical isomers prevent the oxygenation of cannabinoids by COX $2 .^{7}$ On the other hand, (R)-NPX is more active in the processes of metabolic inversion, in particular, by cytochrome $\mathrm{P} 450 \frac{18}{\underline{18}}$ (which also involves ET).$\stackrel{8}{-}$ For that, according to the results of biochemical research, there is no complete understanding, for example about what kind of physicochemical interactions are responsible for the difference in the action of (S)- and (R)-NPX. .16

Taking into consideration the above-mentioned possible involvement of NPX optical isomers in charge transfer processes, it seems promising to use a model one-electron transfer process for studying the chemical nature of the difference between (S)- and (R)isomers. In this connection, the comparison of (S)- and (R)-NPX reactivity in one of the most universal elementary processes, electron transfer, may have not only of a fundamental but also of a practical interest.

The stereoselectivity of the photoinduced partial (exciplex) and full charge transfer (biradical-zwitterion, BZ) in the linked system of (R,S)- and (S,S)-NPX-Nmethylpyrrolidine has been recently reported. $\underline{19-24}$

Since the days of Jabotinsky's works, the photochemical generation of a pair of paramagnetic particles has been used for the modeling of biological processes such as the elementary steps of enzymatic oxygenation and drug-transport protein binding. ${ }^{25-27}$ This approach is promising in several aspects. Firstly, it can be expected that the reactivity of paramagnetic particles, in a first approximation, does not depend 
significantly on the method of their generation. Secondly, a higher concentration of short-lived intermediates in comparison with that in an enzymatic process can be achieved by photogeneration. It allows the use of a variety of physical methods.

In this regard, we are planning to study the chirality impact on the photoinduced processes in (R,S)- and (S,S)-NPX-pyrrolidine dyads, where NPX and a donor are connected by two kind of bridges: flexible and rigid. By the variation of the lengths and structure of the bridges, we suppose to change the spatial donor-acceptor interaction in the dyad diastereomers, since this interaction is believed to determine stereodifferentiation.

We have chosen to use a combination of techniques: fluorescence and chemicallyinduced dynamic nuclear polarization (CIDNP) methods, which have previously been used individually in the study of naproxen dyads. ${ }^{22-24}$ It should be noted that CIDNP is considered to be one of the most informative methods to identify short-lived paramagnetic particles, ${ }^{28}$ and its use together with the fluorescence data can let one perform quantitative analysis of a process.

As a goal, it is planned to establish the main factors affecting the donor-acceptor interaction in (R,S)- and (S,S)-NPX-containing dyads with different bridges. In particular, this could allow us to trace differences in the reactivity of (R)- and (S)-NPX in processes with partial and full charge transfer.

\section{Results and discussion}

\section{Systems under study}

Two pairs of NPX-pyrrolidine dyads, with a flexible (R)-/(S)-NPX-AA-(S)-Pyr 2(a,b) or rigid (R)-/(S)-NPX-CyAA-(S)-Pyr 3(a,b) bridge between the donor and acceptor units, were designed and synthesized (Chart 1, synthesis details are presented in the ESI + ). Thus, (R)- or (S)-NPX 1(a,b) was reacted with 4-aminobutyric acid or (1S,3R)3 -aminocyclopentanecarboxylic acid to give the corresponding NPX-amino acids that upon esterification using (S)-N-methyl-2-pyrrolidinemethanol resulted in the final dyads (R)-/(S)-NPX-AA-(S)-Pyr 2(a,b) or (R)-/(S)-NPX-CyAA-(S)-Pyr 3(a,b). Directly linked (short) (R)-/(S)-NPX-(S)-Pyr dyads 4(a,b) to be used as controls were prepared as described previously. $\frac{20,21}{\mathrm{~S}}$ 


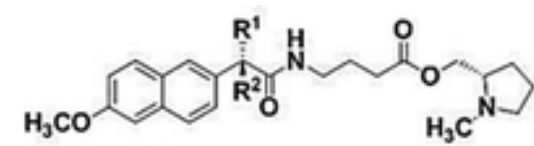

$\mathrm{R}^{1}=\mathrm{H} ; \mathrm{R}^{2}=\mathrm{CH}_{3}(R)-\mathrm{NPX}-\mathrm{AA}-(S) \cdot \mathrm{Pyr}$

$\mathrm{R}^{1}=\mathrm{CH}_{3} ; \mathrm{R}^{2}=\mathrm{H} \quad(S) \cdot \mathrm{NPX}-\mathrm{AA}-(S) \cdot \mathrm{Pyr}$

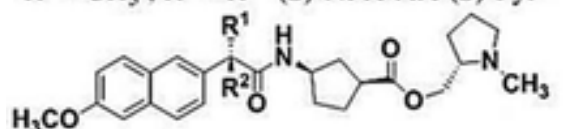

(2b)

$\mathrm{R}^{1}=\mathrm{H} ; \mathrm{R}^{2}=\mathrm{CH}_{3}(R)$-NPX-CyAA-(S)-Pyr $(3 \mathrm{a})$

$\mathrm{R}^{1}=\mathrm{CH}_{3} ; \mathrm{R}^{2}=\mathrm{H} \quad(S)$-NPX-CyAA-(S)-Pyr $(3 \mathrm{~b})$<smiles>COc1ccc2cc([14CH]=O)ccc2c1</smiles>

$\mathrm{R}^{1}=\mathrm{H} ; \mathrm{R}^{2}=\mathrm{CH}_{3}(R)-\mathrm{NPX}-(S)-\mathrm{Pyr}$

$\mathrm{R}^{1}=\mathrm{CH}_{3} ; \mathrm{R}^{2}=\mathrm{H} \quad(S)-\mathrm{NPX}-(S)-\mathrm{Pyr}$

Chart 1 Chemical structure of the synthesized dyads.

\section{Fluorescence quenching of (R,S)- and (S,S)-dyads}

The absorption spectra of both stereoisomers $\mathbf{2}(\mathbf{a}, \mathbf{b})$ and $\mathbf{3}(\mathbf{a}, \mathbf{b})$ demonstrate the same bands as the parent NPX $\mathbf{1 b}$; specifically they display two typical fine-structured UV absorption bands with maxima at 262 and $332 \mathrm{~nm}$ (the spectra are presented previously, $\frac{19-21}{}$ and for both isomers the spectra are identical), which are ascribed to $\pi-$ $\pi^{*}$-type transitions. The fluorescence spectra of $\mathbf{2}(\mathbf{a}, \mathbf{b})$ and $\mathbf{3}(\mathbf{a}, \mathbf{b})$ dyads in acetonitrile are presented in Fig. 1.

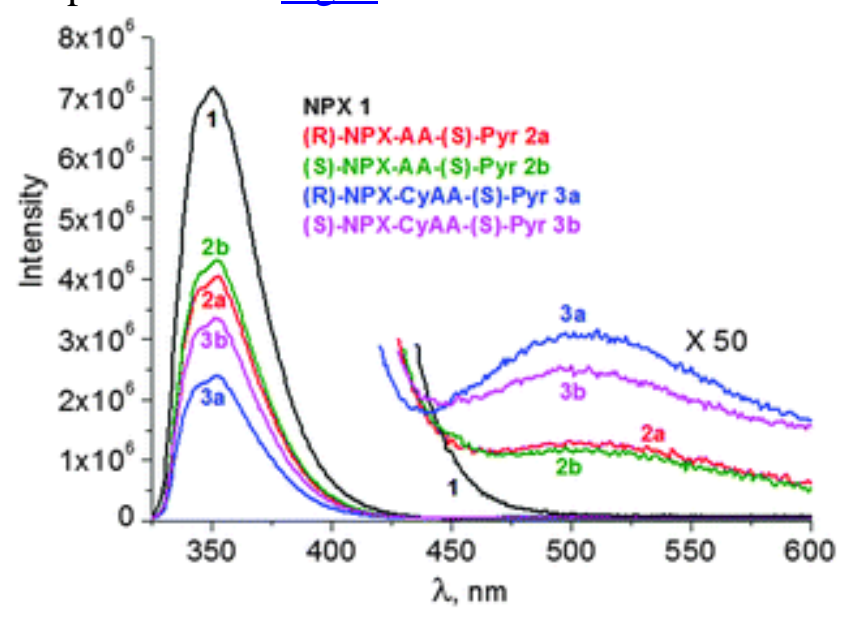

Fig. 1 Fluorescence spectra of $\mathbf{1}, \mathbf{2}(\mathbf{a}, \mathbf{b})$ and $\mathbf{3}(\mathbf{a}, \mathbf{b})$ in acetonitrile $\left(\lambda_{\mathrm{ex}}=320 \mathrm{~nm}\right)$, concentration $\sim 10^{-5} \mathrm{M}$. The inset shows magnified emission spectra in the long wavelength range $(>425 \mathrm{~nm})$.

These spectra are similar to that of the parent NPX but contain an exciplex band in the red region. Thus, in addition to a local excited (LE) state, an exciplex is also formed under UV irradiation. Its concentration in solution and the position of the band's maximum in the fluorescence spectra depend on permittivity. It is worth noting that the fluorescence quantum yield of the $\mathbf{2}(\mathbf{a}, \mathbf{b})$ LE state is higher than that of $\mathbf{3}(\mathbf{a}, \mathbf{b})$. Moreover the exciplex band of $\mathbf{2}(\mathbf{a}, \mathbf{b})$ is much weaker than that of $\mathbf{3}(\mathbf{a}, \mathbf{b})$. 
Typical kinetics curves of the LE state and exciplex are shown in Fig. 2. The two diastereoisomers of $\mathbf{2}(\mathbf{a}, \mathbf{b})$ and $\mathbf{3}(\mathbf{a}, \mathbf{b})$ dyads show biexponential kinetics both for the LE states and for the exciplexes. The LE state's kinetics correspond to two decay times $\left(\tau_{\text {short }}, \tau_{\text {long }}\right)$, and the exciplex kinetics have growth and decay times $\left(\tau_{\text {rise }}, \tau_{\text {fall }}\right)$. The dependence of fluorescence lifetimes on solvent polarity is shown in Fig. 3 for $\mathbf{2}(\mathbf{a}, \mathbf{b})$ and 3(a,b). These curves have been obtained from the experimental data of fluorescence kinetics for dyads in acetonitrile-benzene mixtures $\left(\varepsilon_{\text {acetonitrile }}=36.8, \underline{\underline{29}} \varepsilon_{\text {benzene }}=2.28, \underline{30}\right.$ and the permittivity for the mixtures has been taken from the literature ${ }^{31}$ ). Fig. 3 shows a certain correspondence, on the one hand, between the values of exciplex decay time $\left(\tau_{\text {fall }}\right)$ and LE state long decay time $\left(\tau_{\text {long }}\right)$ and, on the other hand, between the exciplex growth time $\left(\tau_{\text {rise }}\right)$ and LE state short decay time $\left(\tau_{\text {short }}\right)$. This accordance clearly shows the feedback between the processes of the formation and decay of the exciplex and local excited state. This consideration underlies Scheme 1 showing the proposed quenching mechanism.
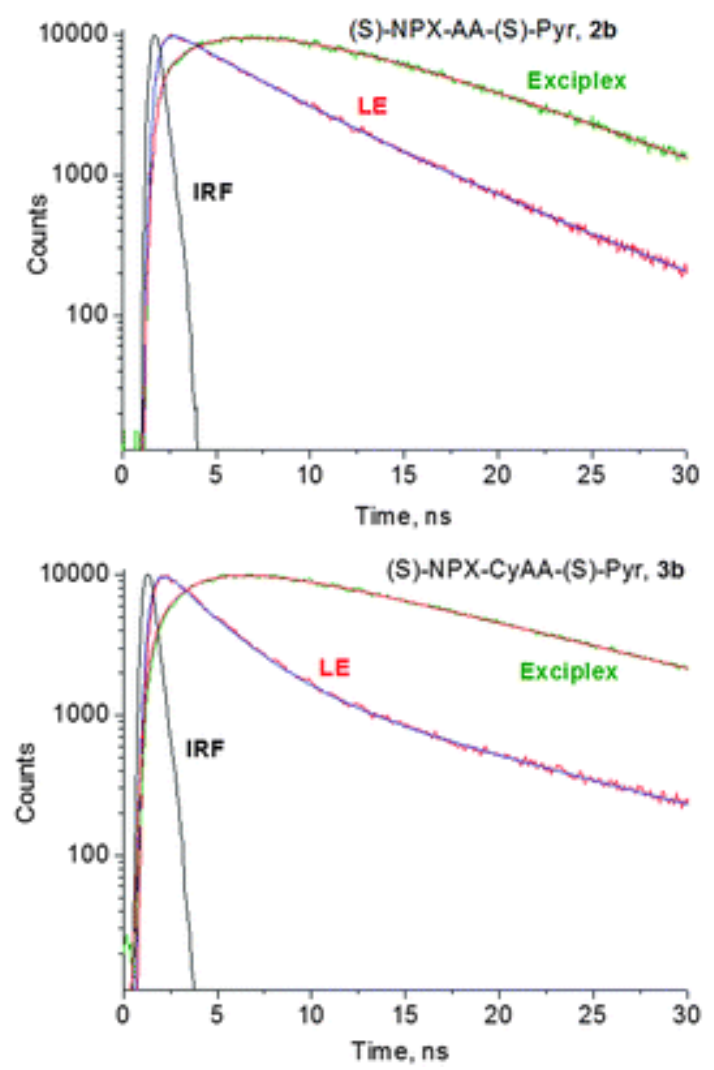

Fig. 2 Fluorescence decay traces of dyad (S)-NPX-AA-(S)-Pyr (2b, top) and (S)NPX-CyAA-(S)-Pyr (3b, bottom) at 351 and $500 \mathrm{~nm}\left(\lambda_{\mathrm{ex}}=320 \mathrm{~nm}\right)$ in acetonitrilebenzene mixture $(\varepsilon=21.55)$. IRF: instrument response function. 

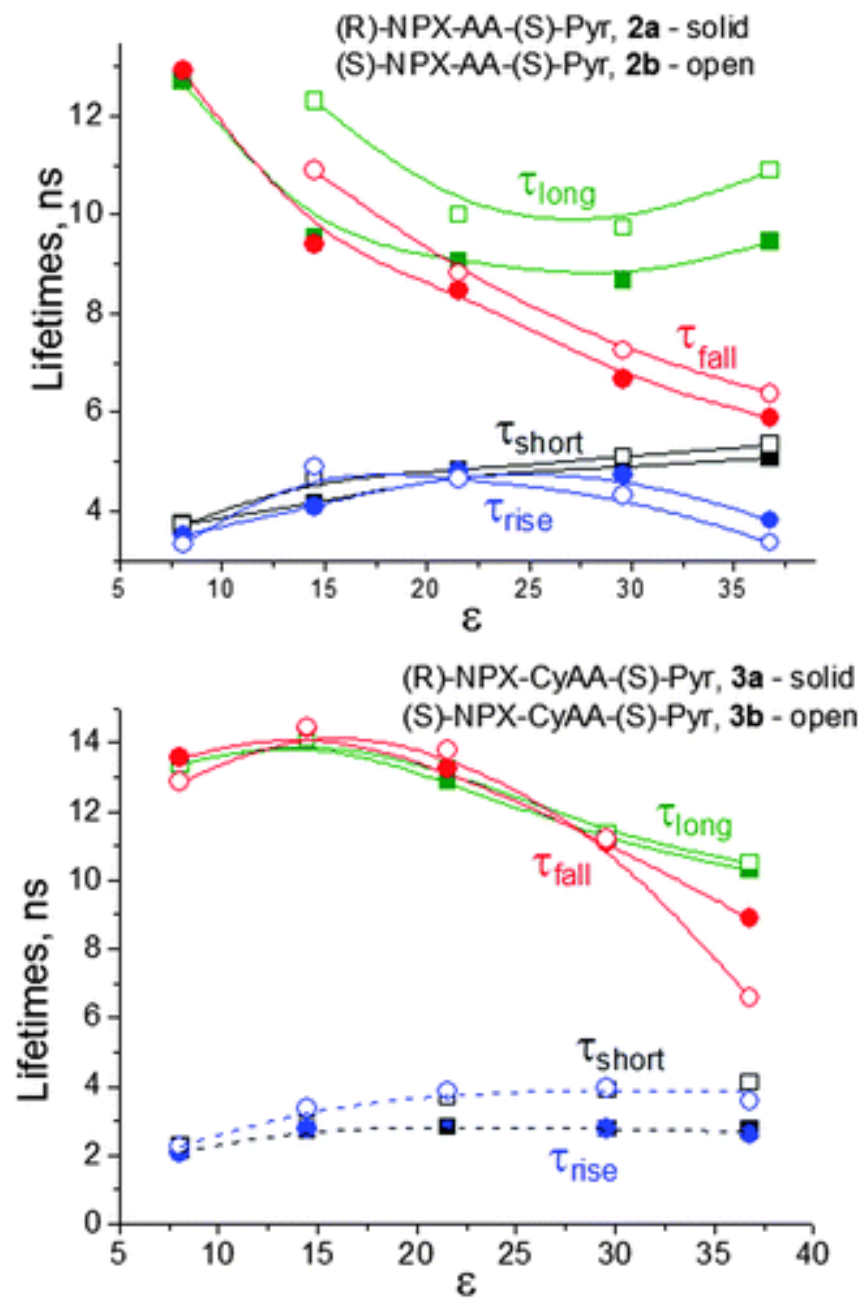

Fig. 3 Dependence on solvent polarity of the fluorescence lifetimes for (R)-/(S)NPX-AA-(S)-Pyr (2(a,b), (top)) and (R)-/(S)-NPX-CyAA-(S)-Pyr (3(a,b),

(bottom)). Local excited state: squares $\left(\tau_{\text {short }}, \tau_{\text {long }}\right)$ and exciplex: circles $\left(\tau_{\text {rise }}, \tau_{\text {fall }}\right)$. Lifetime values are given in the ESI. $\perp$

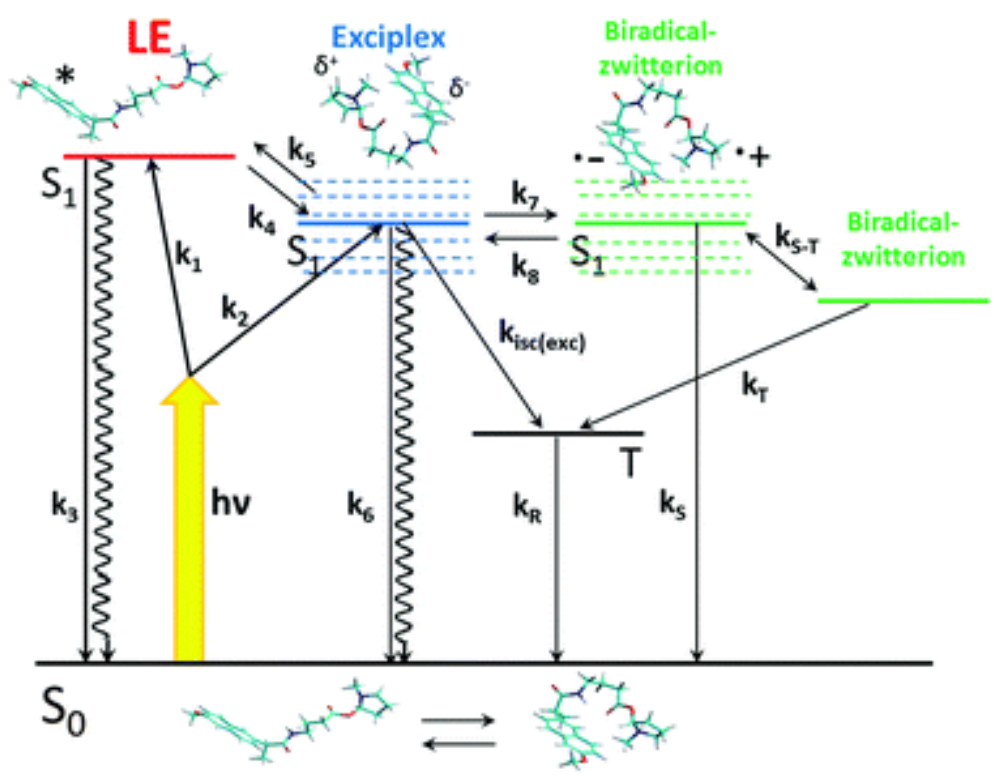


Scheme 1 Quenching mechanism of the NPX chromophore in dyads NPX-AA-Pyr 2(a,b) and NPX-CyAA-Pyr 3(a,b).

This scheme summarizes all the processes taking place in the quenching of the dyad chromophore excitation in the presence of an electron donor. Here, $\mathrm{k}_{1}$ and $\mathrm{k}_{2}$ represent pathways through which different dyad conformations (expanded and folded) transfer into the excited states. The first path $\left(\mathrm{k}_{1}\right)$ is the formation of the LE state from an expanded conformation, whereas the exciplex, in its turn, is generated from a folded conformation $\left(\mathrm{k}_{2}\right)$. So, in rate constant calculations $\mathrm{k}_{1}$ and $\mathrm{k}_{2}$ reflect the amount of different conformations participating in the reaction (about 0.8 and 0.2 , correspondingly). Note that Scheme 1 differs from the scheme proposed earlier for the short $\mathbf{4}(\mathbf{a}, \mathbf{b})$ dyad. $\frac{23,24}{\mathrm{In}}$ that scheme an exciplex is formed only from the local excited state but in our case, for $\mathbf{2}(\mathbf{a}, \mathbf{b})$ and $\mathbf{3}(\mathbf{a}, \mathbf{b})$, the leading edge of the exciplex's kinetic curves is satisfactorily fitted only if we assume the simultaneous formation of both the exciplex and local excited state. This forced us to assume the existence of at least two geometrical conformations of dyad molecules with quite different energies. $\underline{32-34}$

An exciplex is in rapid dynamic equilibrium with the local excited state $\left(\mathrm{k}_{4}, \mathrm{k}_{5}\right)$ and with the biradical-zwitterion $\left(\mathrm{k}_{7}, \mathrm{k}_{8}\right)$. The LE state and exciplex emission are presented as $\mathrm{k}_{3}$ and $\mathrm{k}_{6}$ constants, correspondingly. BZ can be in a singlet or triplet isoenergetic spin state. Spin conversion $\left(\mathrm{k}_{\mathrm{S}-\mathrm{T}}\right)$ is taking place under the influence of magnetic interactions in the paramagnetic centers of BZ. Back ET from both the spin states of BZ leads to the formation of the parent dyads in the singlet ground and excited triplet state with the rate constants $\mathrm{k}_{\mathrm{S}}$ and $\mathrm{k}_{\mathrm{T}}$. Both pathways lead to CIDNP of the dyads in the ground state. They can be separated since the triplet contribution appears delayed by the triplet state lifetime $\left(\mathrm{k}_{\mathrm{R}}\right)$. The exciplex, in its turn, also undergoes internal conversion with the

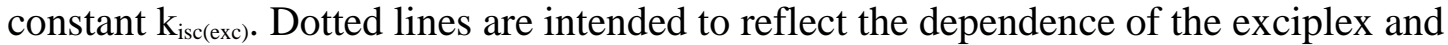
BZ energy level positions on the dielectric constant of the medium (this relationship is shown in Fig. 6 and discussed in detail in the next part).

BZ has been included in the scheme by the analogy with the NPX-Pyr 4(a,b) dyad studied previously. $\stackrel{23,24}{ }$ The conclusion about the equilibrium between the exciplex and BZ has been made on the basis of CIDNP analysis. Kinetic curves for $\mathbf{2}(\mathbf{a}, \mathbf{b})$ and $\mathbf{3}(\mathbf{a}, \mathbf{b})$ dyads have been analyzed by the numerical solution of the system of differential equations using the Runge-Kutta method in the framework of Scheme $1 . \underline{35}$ When solving the differential equation system for all processes in the systems under study, the adequacy of the obtained values could be checked only by comparison with the available kinetic curves (given that we cannot observe the biradical-zwitterion in these experiments).

It is worth emphasizing that the previously studied dyad $\mathbf{4}(\mathbf{a}, \mathbf{b})$ can also be described by this sequence of steps, outlined in $\underline{\text { Scheme } 1 .}$.

Rate constants related to the processes of dyad quenching (Scheme 1) for the $\mathbf{2}(\mathbf{a}, \mathbf{b})$ and $\mathbf{3}(\mathbf{a}, \mathbf{b})$ dyads are shown in Table 1 . The analysis of the data from Table 1 allows us to trace the differences between the diastereomers of the studied dyads and compare the results with those for dyad $\mathbf{4}(\mathbf{a}, \mathbf{b})$. Thus, the largest difference is obtained for the rate constants related to the charge transfer: $\mathrm{k}_{4}$ and $\mathrm{k}_{7}$, with the latter showing an effect only in polar media. The constant $\mathrm{k}_{4}$ is higher for the (a)-isomers of all three dyads (Fig. 4), whereas in the case of $k_{5}$ no systematic dependence is observed. The rate constant $k_{7}$, 
corresponding to the process of the exciplex transformation into BZ, shows more pronounced dependence on solvent polarity than on the optical configuration (Fig. 4).

Table 1 Calculated rate constants $\left(\mathrm{k}_{\mathrm{i}} \times 10^{-8} \mathrm{~s}^{-1}\right)$ for the pathways outlined in Scheme 1 at different permittivities for the NPX-AA-Pyr 2(a,b) and NPX-CyAA-Pyr 3(a,b) dyads
(R)-NPX-AA-(S)-Pyr, 2a (R)-NPX-CyAA-(S)-Pyr, 3a
$\begin{array}{lllllllllllll}\boldsymbol{\varepsilon} & \mathbf{k}_{3} & \mathbf{k}_{4} & \mathbf{k}_{5} & \mathbf{k}_{6} & \mathbf{k}_{7} & \boldsymbol{\varepsilon} & \mathbf{k}_{3} & \mathbf{k}_{4} & \mathbf{k}_{5} & \mathbf{k}_{6} & \mathbf{k}_{7}\end{array}$

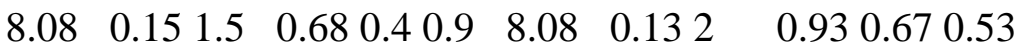

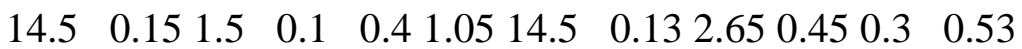

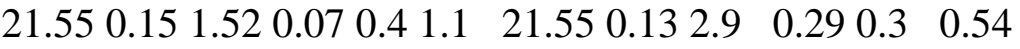

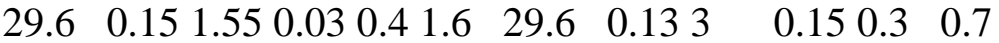

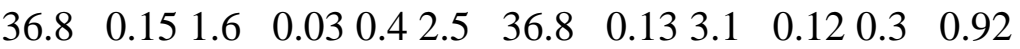

\section{(S)-NPX-AA-(S)-Pyr, 2b (S)-NPX-CyAA-(S)-Pyr, 3b \\ $\begin{array}{lllllllllllllll}\boldsymbol{\varepsilon} & \mathbf{k}_{3} & \mathbf{k}_{4} & \mathbf{k}_{5} & \mathbf{k}_{6} & \mathbf{K}_{7} & \boldsymbol{E} & \mathbf{k}_{3} & \mathbf{K}_{4} & \mathbf{k}_{5} & \mathbf{k}_{6} & \mathbf{k}_{7}\end{array}$ \\ $\begin{array}{llllllllllll}8.08 & 0.15 & 1.2 & 0.42 & 0.63 & 1.0 & 8.08 & 0.13 & 1.5 & 0.9 & 0.95 & 0.58\end{array}$

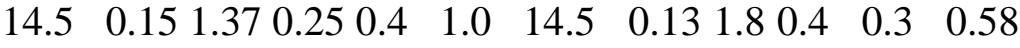 \\ $21.550 .151 .38 \quad 0.1 \quad 0.4 \quad 1.2 \quad 21.550 .13 \quad 1.90 .22 \quad 0.3 \quad 0.58$

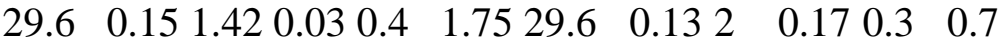

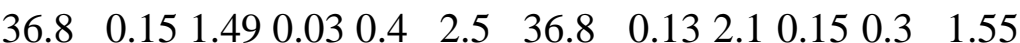

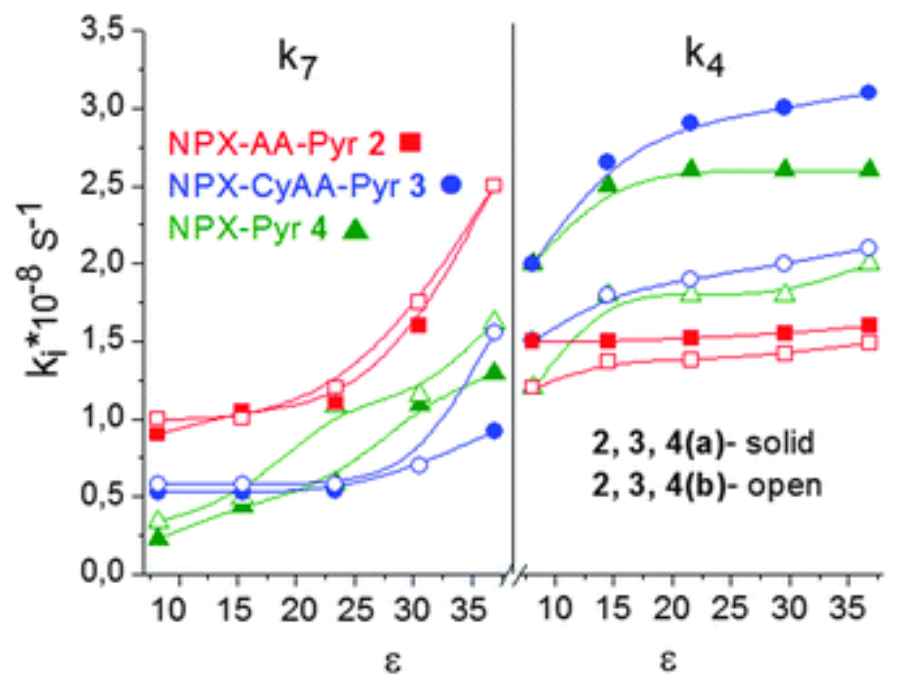

Fig. 4 Correlation between the rate constants $\mathrm{k}_{4}$ (LE state to exciplex transition), and $\mathrm{k}_{7}$ (exciplex to BZ transition) and solvent polarity (Scheme 1 and Table 1) for 2(a,b), 3(a,b) and 4(a,b).

The dependence of the fluorescence quantum yields of the local excited state $\left(\Phi_{\mathrm{LE}}\right)$ and exciplex $\left(\Phi_{\text {exc }}\right)$ on solvent polarity for both (a)- and (b)-diastereomers is shown in Fig. 5 . The analysis of these curves let us conclude that (a)-diastereomers of the dyads comprising (R)-NPX and (S)-N-methylpyrrolidine are more inclined to charge transfer (CT) because the rate constants of exciplex formation and the quantum yields are larger 
than those for (b)-isomers. As for (S)-NPX, the combined analysis of the exciplex fluorescence quantum yield as well as the corresponding rate constant indicates that in this case the exciplex should form slightly slower and decompose quickly. The latter is reflected in the lower $\Phi_{\text {exc }}$ and larger $\Phi_{\mathrm{LE}}$ of the dyads consisting of (S)-NPX. The comparison of fluorescence quantum yields for all three dyads demonstrates that the stereodifferentiation degree depends on both the bridge's length and its structure. Thus, $\Phi_{\text {exc }}$ for (a)- and (b)-diastereomers differ the most for the short dyad 4, and much less for dyad $\mathbf{2}$ with a flexible bridge. The rigid dyad $\mathbf{3}$ shows stereodifferentiation of $\Phi_{\text {exc }}$ and $\Phi_{\mathrm{LE}}$. The difference in values for the (a)- and (b)-isomers depends on the permittivity less than in other cases. It can be supposed that the contribution of the CT states in the quenching process is determined to a larger extent by the mutual donoracceptor position than by environment effects.
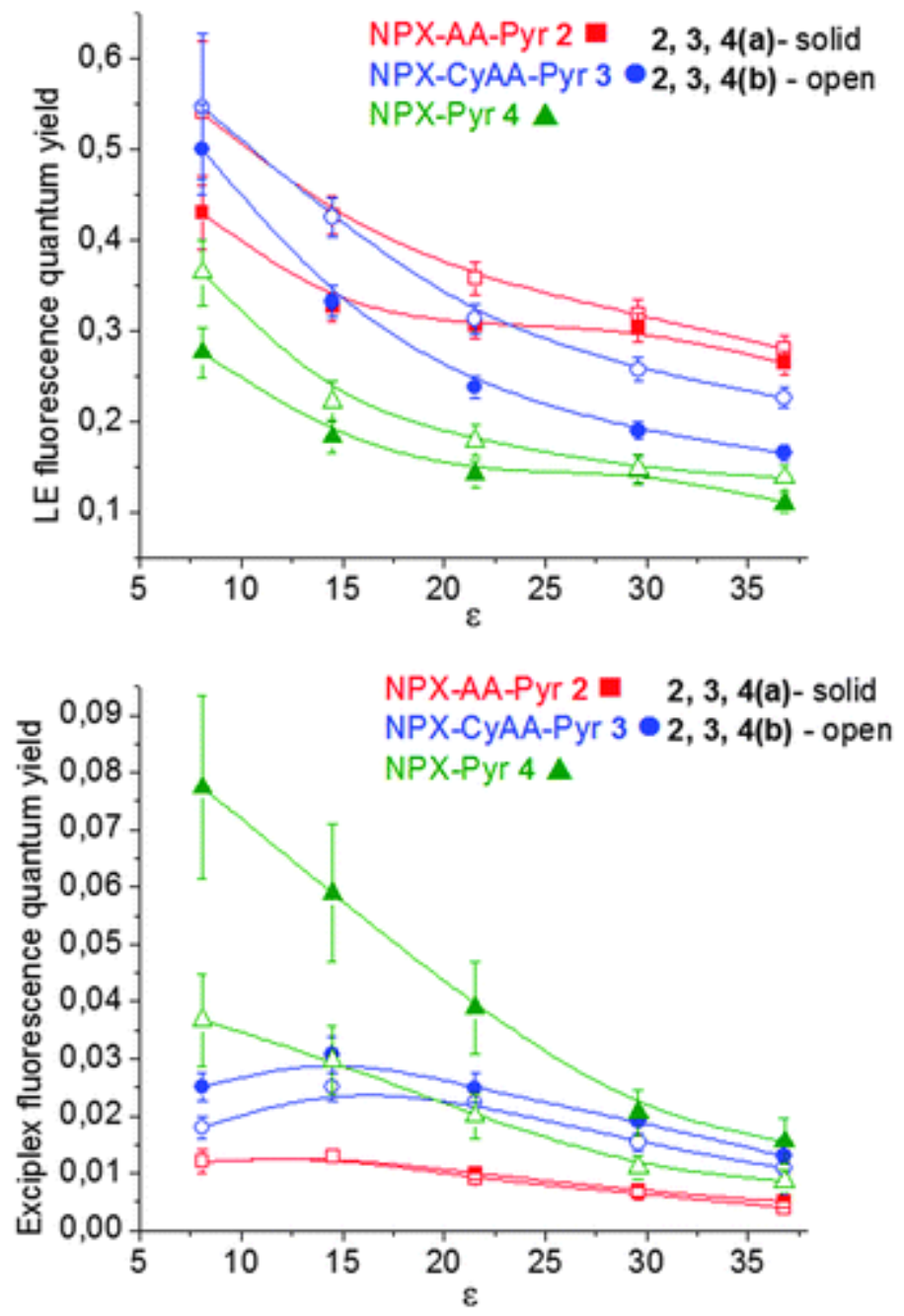

Fig. 5 Fluorescence quantum yield (local excited state, LE: top, exciplex: bottom) dependence on solvent polarity for $\mathbf{2}(\mathbf{a}, \mathbf{b}), \mathbf{3}(\mathbf{a}, \mathbf{b})$ and $\mathbf{4}(\mathbf{a}, \mathbf{b})$. These values have been estimated using NPX in acetonitrile as a standard $\left(\Phi_{\mathrm{NPX}}=0.47^{21}\right)$, and numerical values are given in the ESI. \pm

\section{CIDNP effects in (R,S)- and (S,S)-dyads and their relationship with the exciplex-biradical-zwitterion balance}


The high sensitivity of the spin effects in the processes with partial and full CT to polar environments is well-known. $\underline{34,37-40}$ This impact of polarity on CIDNP efficiency has been shown earlier for the photoinduced ET in the short dyad NPX-Pyr 4(a,b). $\underline{22,24}$ Dyads NPX-AA-Pyr 2(a,b) and NPX-CyAA-Pyr 3(a,b) also demonstrate the dependence of ${ }^{1} \mathrm{H}$ CIDNP effects at $\mathrm{N}$-methylpyrrolidine fragments, obtained with the help of a pseudo-steady state pulses sequence,,$\underline{41}$ on the solvent permittivity (Fig. 6 , only (b)-diastereomers are shown). For these dyads the appearance of negative integral polarization of the protons of the N-methylpyrrolidine fragments of dyads $\mathbf{2}(\mathbf{a}, \mathbf{b})$ and $\mathbf{3}(\mathbf{a}, \mathbf{b})$, according to the Kaptein rule,,$\underline{28}$ corresponds to the back electron transfer in the singlet spin state of BZ. BZ is in turn obtained from the dyad's singlet excited state.

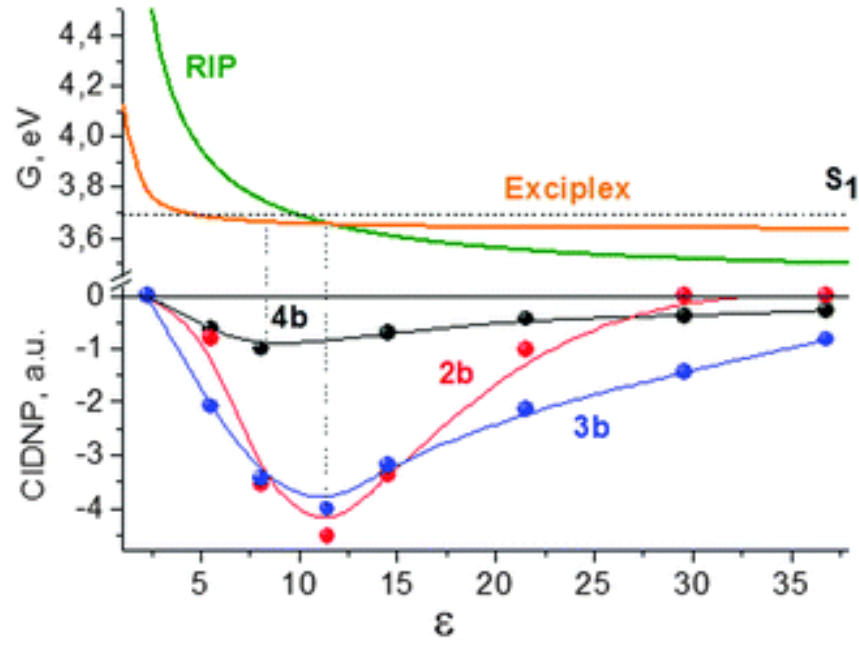

Fig. 6 Dependence of the free energies of the radical ion pair (RIP) of the Nmethylpyrrolidine ${ }^{22}$ radical cation, and the methoxynaphthalene radical anion, and the exciplex in this system, calculated using the Rehm-Weller equation ${ }^{36}$ (top). Dependence of the CIDNP effect on solvent permittivity for (S)-NPX-AA-(S)-Pyr 2b, (S)-NPX-CyAA-(S)-Pyr 3b and (S)-NPX-(S)-Pyr 4b (bottom).

The position of the dependence extremum (Fig. 6) indicates that in the dyads with long bridges $\mathbf{2}(\mathbf{a}, \mathbf{b})$ and $\mathbf{3}(\mathbf{a}, \mathbf{b})$ maximal CIDNP is generated at higher polarities where the extremum corresponds to the intersection point of the exciplex and BZ terms. Thus, for dyad $\mathbf{4}(\mathbf{a}, \mathbf{b})$ the equilibrium is shifted toward the exciplex, whereas for dyads $\mathbf{2}(\mathbf{a}, \mathbf{b})$ and $\mathbf{3}(\mathbf{a}, \mathbf{b})$ it is shifted in the direction of the BZ. Indeed, for both the $\mathbf{2}(\mathbf{a}, \mathbf{b})$ and $\mathbf{3}(\mathbf{a}, \mathbf{b})$ dyads the exciplex quantum yields are significantly lower than those for the $\mathbf{4}(\mathbf{a}, \mathbf{b})$ dyads (Fig. 5). This observation supports the above-mentioned concept that the exciplex is formed in the region of the closest approach of the donor and acceptor. ${ }^{34}$ In essence, there is a certain correlation between the donor-acceptor distance and the biradicalzwitterion-exciplex balance. To confirm this hypothesis, as well as to probe the difference between the CIDNP polarity dependence for (a)- and (b)-diastereomers, CIDNP effect calculations in media with different permittivity have been performed. It

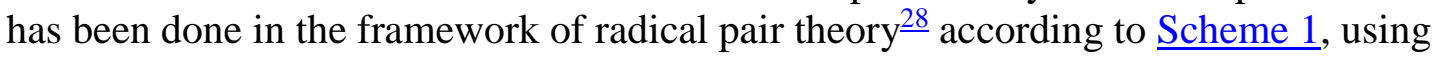
the rate constants from Table 1. The other parameters used for the calculation are given in the ESI.I

The curves in Fig. 7 show satisfactory agreement between theory and experiment. The greatest discrepancies are observed at high polarities. There are several reasons for this: first, the theory has been developed for the motion of the paramagnetic centers of the dyads in the Coulomb field, but it is known that in highly polar media charged particles 
act as neutrals. $\frac{28}{2}$ The second reason is a change in the ratio of the recombination rates from the singlet and triplet BZ spin states: $\mathrm{k}_{\mathrm{S}}$ and $\mathrm{k}_{\mathrm{T}}$, whose values are a function of polarity. $\underline{22}$ These changes are not considered in our calculations.
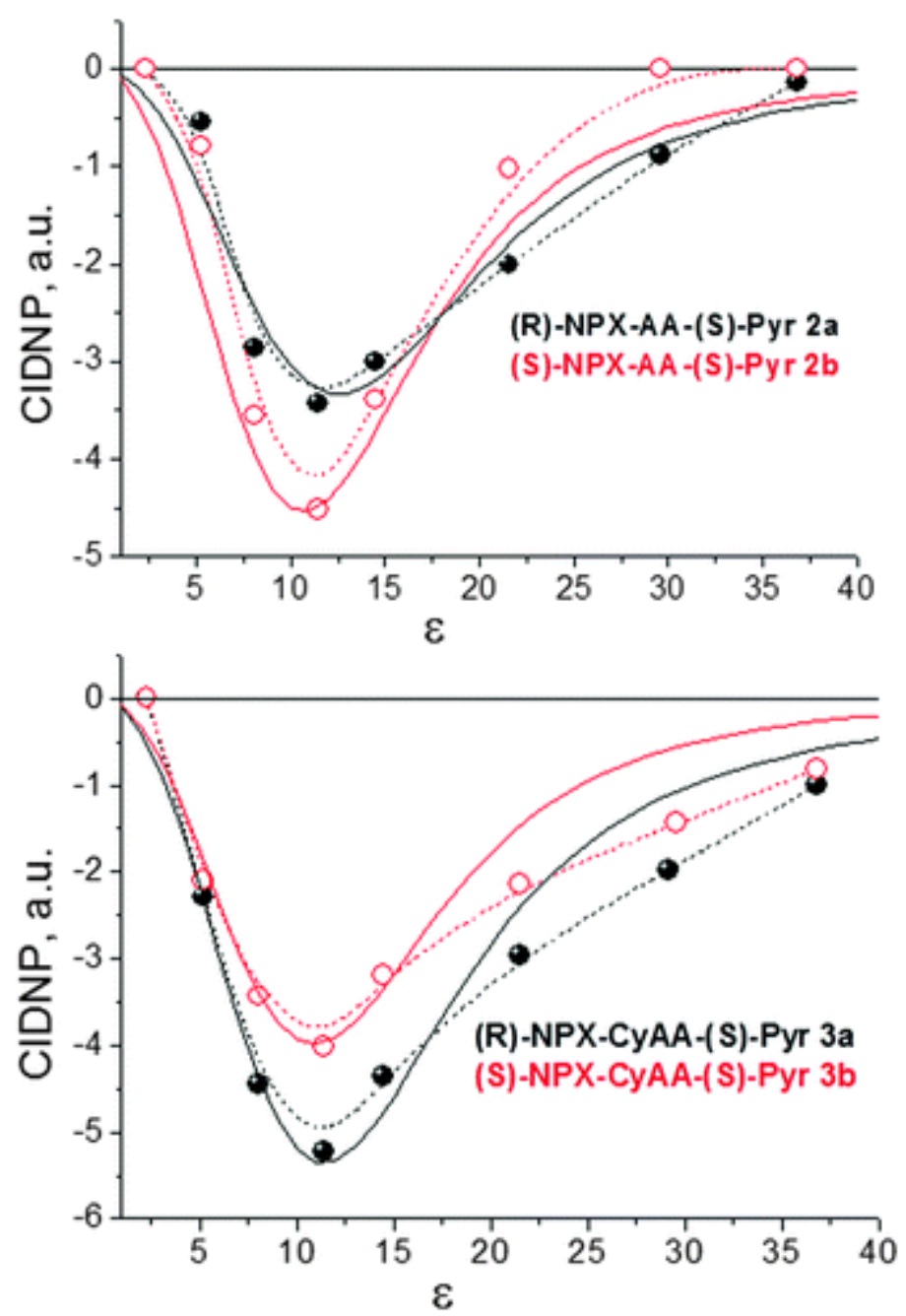

Fig. 7 Dependence of CIDNP effects on solvent polarity for 2(a,b) (top) and 3(a,b) (bottom). The solid lines are calculated using the solution of spin chemistry master equation. $\frac{28,42,43}{}$

Thus, simultaneous analysis of CIDNP and fluorescence data allows us to trace all short-lived intermediates involved in the excitation quenching of dyads $\mathbf{2}(\mathbf{a}, \mathbf{b})$ and 3(a,b): the LE state, exciplex, and BZ. All of them in any manner depend on the solvent polarity. However, only in the case of CIDNP is the source of its dependence completely understood; it can be explained by a shift of the exciplex-biradicalzwitterion equilibrium towards the latter with increasing polarity.

It is interesting to look at how the fluorescence quantum yields of the exciplex ( $\left.\Phi_{\text {exc }}\right)$ and local excited state $\left(\Phi_{\mathrm{LE}}\right)$ are related to CIDNP efficiency at different polarities. The analysis of these relations can help to identify the main factors that affect the quantum yields $\Phi_{\text {exc }}$ and $\Phi_{\mathrm{LE}}$. The relation between CIDNP efficiency for the diastereoisomers of both dyads and the fluorescence quantum yields $\Phi_{\text {exc }}$ in the media of different permittivities is shown in Fig. 8. 

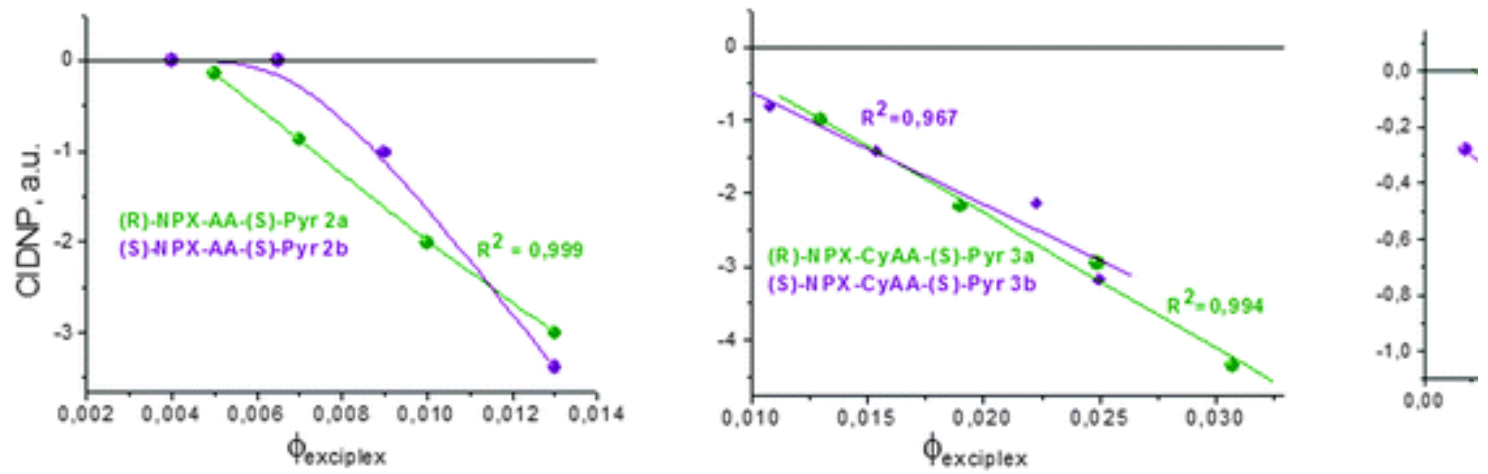

Fig. 8 Correlation between CIDNP effects and the exciplex's fluorescence quantum yields for 2(a,b) (left), 3(a,b) (middle), and 4(a,b) (right).

As can be seen from Fig. 8, the dependence is almost linear, especially for the (a)diastereomers. This fully confirms the previously mentioned conclusion, that increasing the solvent permittivity shifts the equilibrium towards BZ. This correlation allows us to specify the difference between the properties of the (a)- and (b)-diastereomer exciplexes. Because $\Phi_{\text {exc }}$ for the (a)-isomers depends on the CIDNP efficiency almost linearly, it means that the states with charge transfer have a major contribution to the processes of the exciplex formation and decay. Obviously, $\Phi_{\text {exc }}$ of the (b)-diastereomers, which does not show a linear relationship, depends not only on processes 4 and 7 but also on process 5 .

On the other hand, the analysis of the biexponential kinetics of the LE state's fluorescence quenching demonstrates that the exciplex contributes in this process as well: one exciplex decay channel is its back transformation into a LE state (Scheme 1). The relation between $\Phi_{\mathrm{LE}}$ and CIDNP (not shown), which is not linear, indicates that besides the exciplex back transformation into the LE state, there are other processes which are less sensitive to the change in polarity.

To summarize the results of this section we can conclude that additional confirmation of the reactional $\underline{\text { Scheme } 1}$ by an independent method (CIDNP analysis) has been obtained. The CIDNP calculation also confirms the existence of the difference between the CIDNP effects of (a)- and (b)-diastereomers in solvents with different permittivities.

\section{Theoretical DFT conformational analysis of (R,S)- and (S,S)-dyads}

Because chiral isomers differ in the mutual arrangement of the substituents at a chiral center, one can expect that quantum chemical (QC) conformational analysis of enantiomers and diastereomers can help to understand the source of differences in their properties. The majority of work performed in this area is devoted to the conformational analysis of epimers, as well as computational modeling and materials design based on molecular chirality. $\underline{.4-47}$

QC calculations in this work were performed using GAUSSIAN-09 Revision C.1. $\underline{48}$ The most popular DFT method (B3LYP $\frac{49,50}{}$ ) with the basis set $6-31 \mathrm{G}(\mathrm{d})^{\frac{51}{1}}$ was used for potential energy surface (PES) scanning and was followed by geometry optimization of the stable conformers found during PES scanning. The structures determined as global minima of the conformational PES were re-optimized using the extended basis set 6- 
$311 \mathrm{G}(\mathrm{d}, \mathrm{p}) . \underline{52}$ Calculations of vibrational frequencies, enthalpies and Gibbs free energies were performed in the same approximation. Thermodynamic parameters were calculated for the standard conditions (gas phase, $298.15 \mathrm{~K}$ and $1 \mathrm{~atm}$ ) both in the gas phase and in the acetonitrile-benzene binary solvent. The solvent effect was described using the IEFPCM polarized continuum model of Tomasi. $\frac{53}{\text { Careful conformational }}$ analysis was carried out in dyads $\mathbf{4 a}$ and $\mathbf{4 b}$ (Chart 1). The conformational PES was scanned sequentially on five rotation axes of the corresponding single bonds between the cyclic moieties of the compounds (technical details are given in the ESI result, a set of stable compounds were obtained. It was found that the global minima (4a and $4 \mathbf{b}$ ) on the PES correspond to nearly similar spatial structures, which differ only in the asymmetric C atom of NPX (Fig. 9). The Maxwell-Boltzmann distribution of the stable conformers was estimated from the Gibbs free energy. It was found that the populations of the most stable conformations for both epimers are similar (28\% and $26 \%$ for $\mathbf{4 a}$ and $\mathbf{4 b}$ respectively). It may be concluded from our theoretical estimations that the chirality of the structures does not impact significantly the energy state distribution of the conformers.

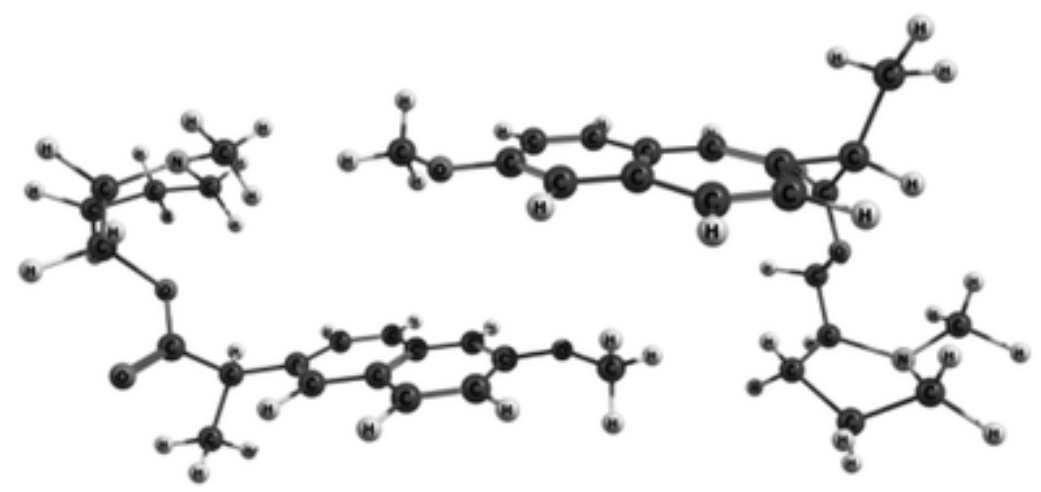

Fig. 9 The structure of epimers $\mathbf{4 a}$ (left) and $\mathbf{4 b}$ (right) correspond to the global minima on the conformational PES of the molecules (B3LYP/6-311G(d,p) optimization).

Conformational analysis of $\mathbf{4 a}$ and $\mathbf{4 b}$ around 1,2 and 5 axes allows us to localize stable conformers of the dyads with a flexible $(\mathbf{2 a}, \mathbf{2} \mathbf{b})$ and rigid $(\mathbf{3 a}, \mathbf{3 b})$ bridge at the B3LYP/6-311G(d,p) level of theory. As it was mentioned above for $\mathbf{4 a}$ and $\mathbf{4 b}$, the equilibrium structures of the epimers are similar and differ only in the asymmetric center of naproxen. The thermodynamic parameters (enthalpy and Gibbs free energies) of the epimers were calculated, and the relative values of thermodynamic potentials with a relative energy of $\mathbf{2 - 4 a , b}$ are shown in Table 2 . The difference in the values of $\mathrm{H}^{\circ}$ and $\mathrm{G}^{\circ}$ for each epimer pair does not exceed $2 \mathrm{~kJ} \mathrm{~mol}^{-1}$ and, apparently, lies within the error of the theoretical estimation.

Table 2 Enthalpies $\left(\Delta \mathrm{H}^{\circ}\right)$ and Gibbs free energies $\left(\Delta \mathrm{G}^{\circ}\right)$ of dyads $2-\mathbf{4}$ relative to the $\mathrm{R}, \mathrm{S}$-epimer (a) $\left(\mathrm{kJ} \mathrm{mol}^{-1}\right)$

\section{Without solvent MeCN : PhH (60 : $40 \mathrm{v}: \mathrm{v})$}

\begin{tabular}{|c|c|c|}
\hline Structure ID $\Delta \mathbf{H}^{\circ}$ & $\Delta \mathbf{G}^{\circ}$ & $\Delta \mathbf{H}^{\circ}$ \\
\hline+0.4 & +1.5 & +0.3 \\
\hline
\end{tabular}




\section{Without solvent MeCN : PhH (60 : $40 \mathrm{v}: \mathrm{v})$}

$\begin{array}{lllll}\text { Structure } \mathbf{I D} & \boldsymbol{\Delta} \mathbf{H}^{\circ} & \mathbf{\Delta G}^{\circ} & \boldsymbol{\Delta} \mathbf{H}^{\circ} & \boldsymbol{\Delta} \mathbf{G}^{\circ} \\ \text { 3a } & -1.7 & -0.4 & -0.1 & -0.4 \\ \mathbf{3 b} & & & & \\ \mathbf{4 a} & -0.2 & -0.4 & -0.4 & -0.9 \\ \mathbf{4 b} & & & & \end{array}$

Based on these results, we can conclude that there is no significant difference in the energy parameters of the dyads, which could reliably explain the experimentally observed differences in the photoinduced processes in diastereomers $\mathbf{2}-\mathbf{4}(\mathbf{a}, \mathbf{b})$.

\section{Conclusions}

\section{Remarks concerning features of the behaviour of dyads with (S)- and (R)- naproxen}

It is interesting to compare the peculiar properties of the (R,S)- and (S,S)-NPX-AAPyr, NPX-CyAA-Pyr, NPX-Pyr dyad reactivity in the model charge transfer (CT) processes with the difference between the activity of (R)- and (S)-NPX in biological systems. Namely, only (S)-NPX is a real inhibitor of arachidonic acid oxygenation $\underline{16}$ (anti-inflammatory effect) but all 2-aryl propionyl derivatives are potent inhibitors of endocannabinoid oxygenation ${ }^{7}$ (analgetic effect) and (R)-NPX more actively undergoes chiral metabolism. $\stackrel{8}{ }$ Our results show the prevailing of the $(\mathrm{R}, \mathrm{S})$-dyad exciplex fluorescence quantum yields ( $\Phi_{\text {exc }}$, up to two times) and the rate constants of the exciplex formation $\left(\mathrm{k}_{4}\right.$, in half times), as well as the different CIDNP effects of the optical isomers.

The difference between $\Phi_{\text {exc }}$ and $\mathrm{k}_{4}$ lets us suggest that the contribution of the CT processes is larger for dyads comprising (R)-NPX. This suggestion is also confirmed by the linear relation between $\Phi_{\text {exc }}$ of the (R,S)-dyad isomers and the CIDNP efficiency, which is completely determined by the equilibrium exciplex-biradical-zwitterion.

According to these results, it can be assumed that (R)-NPX should be more active in the processes of chiral metabolism by the action of cytochrome P450, which involves electron transfer. ${ }^{18}$ Indeed, in the oxidative metabolism of (R)-/(S)-NPX by the microsomal fraction of $\mathrm{P} 450$, the $\mathrm{v}_{\max } / \mathrm{K}_{\mathrm{m}}$ ratio is bigger at 1.3 times that for the $(\mathrm{R})$ -

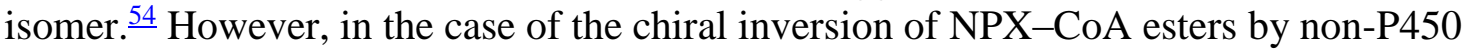
pathways (AMACR and other transferases), the (R)-isomer demonstrates a many times higher activity than that of the (S)-isomers. $\frac{8,12,13,55}{}$

For (S)-NPX, it is known that it acts as a weak reversible inhibitor of COX $2 .{ }^{7}$ Since we believe that our model charge transfer reaction might be reminiscent of donor-acceptor binding, the smaller $\Phi_{\text {exc }}$ of the (S,S)-dyads and the larger $\Phi_{\mathrm{LE}}$ support the idea of higher (S)-NPX binding reversibility. Note that this conclusion is in agreement with the results of biochemical research. ${ }^{?}$ 
Altogether, the obtained results have demonstrated that the stereodifferentiation of diastereomeric (R,S)- and (S,S)-dyads depends on the length of the bridge and on its structure. The relative proximity of the donor and the acceptor results in the largest difference in the reactivity of the diastereomers. This indicates that differences in the reactivity of the optical isomers can be sensitive to the relative position of partners, for example, in active sites.

\section{Acknowledgements}

The work was supported by the Russian Foundation for Fundamental Research (14-0300192, 14-03-00692). All QS calculations were carried out on a cluster computer in the regional center for shared computer equipment at the Ufa Institute of Chemistry of RAS.

\section{Notes and references}

1. G.-Q. Lin, Q.-D. You and J. F. Cheng, Chiral Drugs: Chemistry and Biological Action, John Wiley \& Sons Inc., New Jersey, USA, 1st edn,

2011 Search PubMed

2. K. Krasulova, M. Siller, O. Holas, Z. Dvorak and P. Anzenbacher, Xenobiotica,

2015, 1-10 Search PubMed

3. Q. Shen, L. Wang, H. Zhou, H. Jiang, L. Yu and S. Zeng, Acta Pharmacol. Sin.,

2013, 34, 998-1006 CrossRef CAS PubMed

4. C.-R. Chong, N. E. Drury, G. licari, M. P. Frenneaux, J. D. Horowitz, D. Pagano and B. C. Sallustio, Eur. J. Clin. Pharmacol., 2015, 1-

7 Search PubMed 
5. A. M. Evans, Eur. J. Clin. Pharmacol., 1992, 42, 237-

$256 \underline{\text { CrossRef }} \underline{\text { CAS PubMed }}$

6. R. J. Flower, Pharmacol. Rev., 1974, 26, 33-67 CAS

7. K. C. Duggan, D. J. Hermanson, J. Musee, J. J. Prusakiewicz, J. L. Scheib, B. D. Carter, S. Banerjee, J. A. Oates and L. J. Marnett, Nat. Chem. Biol., 2011, 7,

803-809 CrossRef PubMed

8. T. J. Woodman, P. J. Wood, A. S. Thompson, T. J. Hutchings, G. R. Steel, P. Jiao, M. D. Threadgill and M. D. Lloyd, Chem. Commun., 2011, 47, 7332-

$7334 \underline{\mathrm{RSC}}$

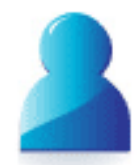

9. M. D. Lloyd, D. J. Darley, A. S. Wierzbicki and M. D. Threadgill, FEBS J.,

2008, 275, 1089-1102 CrossRef CAS PubMed

10. C.-S. Chen, W.-R. Shieh, P.-H. Lu, S. Harriaman and C.-Y. Chen, Biochim.

Biophys. Acta, 1991, 1078, 411-417 CrossRef $\underline{\text { CAS }}$ 
11. R. D. Knihincki, R. O. Day and K. M. Williams, Biochem. Pharmacol., 1991,

42, 1905-1911 CrossRef

12. C. Sevoz, E. Benoit and T. Buronfosse, Drug Metab. Dispos., 2000, 28, 398-

402 CAS

13. M. P. Knadler and S. D. Hall, Chirality, 2004, 16, 379-

387 CrossRef PubMed

14. F. Jamali, R. Lovlin and G. Aberg, Chirality, 1997, 9, 29-

31 CrossRef CAS PubMed

15. D. D. Leipold, D. Kantoci, E. D. Murray Jr., D. D. Quiggle and W. J. Wechter,

Chirality, 2004, 16, 379-387 CrossRef CAS PubMed

16. K. C. Duggan, M. J. Walters, J. Musee, J. M. Harp, J. R. Kiefer, J. A. Oaters and L. J. Marnett, J. Biol. Chem., 2010, 285, 34950- 
17. W. F. Kean, C. J. L. Lock, J. Rischke, R. Butt, W. W. Buchanan and H. Howard-Lock, J. Pharm. Sci., 1989, 78, 324-

327 CrossRef CAS PubMed

18. J. O. Miners, S. Coulter, R. H. Tukey, M. E. Veronese and D. J. Birkett, Biochem. Pharmacol., 1996, 51, 1003-

1008 CrossRef CAS PubMed

19. U. Pischel, S. Abad and M. A. Miranda, Chem. Commun., 2003, 1088-

1089 RSC

20. S. Abad, U. Pischel and M. A. Miranda, Photochem. Photobiol. Sci., 2005, 4,

69-74 CAS

21. M. C. Jimenez, U. Pischel and M. A. Miranda, J. Photochem. Photobiol., C,

2007, 8, 128-142 CrossRef CAS

22. I. M. Magin, N. E. Polyakov, E. A. Khramtsova, A. I. Kruppa, Yu. P.

Tsentalovich, T. V. Leshina, M. A. Miranda, E. Nuin and M. L. Marin, Chem.

Phys. Lett., 2011, 516, 51-55 $\underline{\text { CrossRef }} \underline{\mathrm{CAS}}$ 
23. E. A. Khramtsova, V. F. Plyusnin, I. M. Magin, A. I. Kruppa, N. E. Polyakov, T. V. Leshina, E. Nuin, M. L. Marin and M. A. Miranda, J. Phys. Chem. B, 2013,

117, 16206-16211 CrossRef CAS PubMed

24. I. M. Magin, N. E. Polyakov, E. A. Khramtsova, A. I. Kruppa, A. A. Stepanov,

P. A. Purtov, T. V. Leshina, Yu. P. Tsentalovich, M. A. Miranda and E. Nuin, et

al. , Appl. Magn. Reson., 2011, 41, 205-220 CrossRef CAS

25. F. I. Ataullahanov and A. M. Jabotinsky, Biofizika, 1975, 20, 596-

601 Search PubMed

26. M. S. Afanasyeva, M. B. Taraban, P. A. Purtov, T. V. Leshina and C. B.

Grissom, J. Am. Chem. Soc., 2006, 128, 8651-

8658 CrossRef CAS PubMed

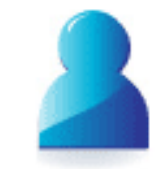

27. N. E. Polyakov, M. B. Taraban and T. V. Leshina, Photochem. Photobiol., 2004,

80, 565-571 CrossRef CAS PubMed

28. K. M. Salikhov, Yu. N. Molin, R. Z. Sagdeev and A. L. Buchachenko, Spin Polarization and Magnetic Effects in Radical Reactions, Akademiai Kiado,

Budapest, Hungary, 1984 Search PubMed 
29. G. P. Cunningham, J. A. Vidulich and R. L. Kay, J. Chem. Eng. Data, 1967, 12,

336-337 CrossRef CAS

30. A. A. Mariott and E. R. Smith, Table of Dielectric Constants of Pure Liquids,

NBS, Washington, DC, 1951 Search PubMed

31. Y. J. Ahadov, Dielectricheskie Svoystva Binarnyh Rastvorov, Nauka, Russia,

1977 Search PubMed

32. I. Azumaya, H. Kagechika, Y. Fujiwara, M. Itoh, K. Yamaguchi and K. J.

Shudo, J. Am. Chem. Soc., 1991, 113, 2833-

2838 CrossRef $\underline{\text { CAS }}$

33. S. Olsen and R. H. McKenzie, J. Chem. Phys., 2012, 137,

164319 CrossRef PubMed
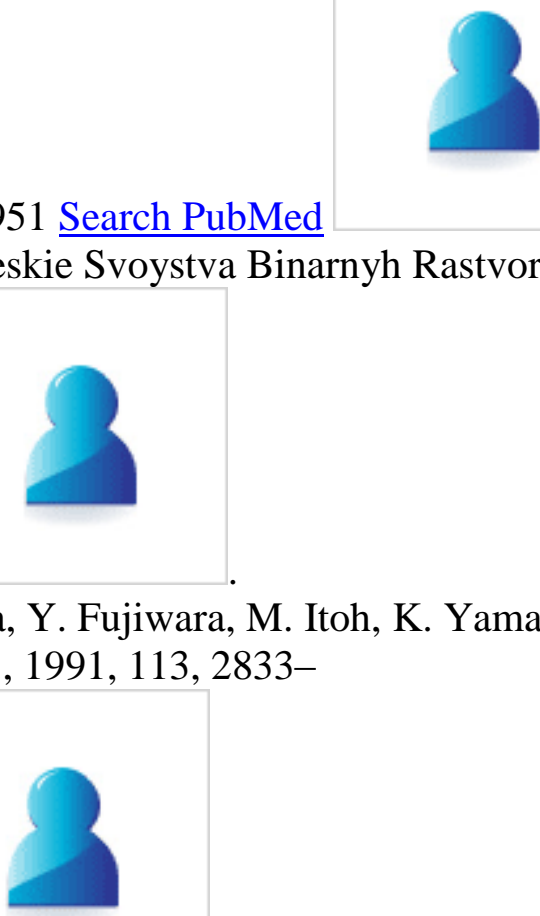

34. K. Bhattacharyya and M. Chowhurry, Chem. Rev., 1993, 93, 507-
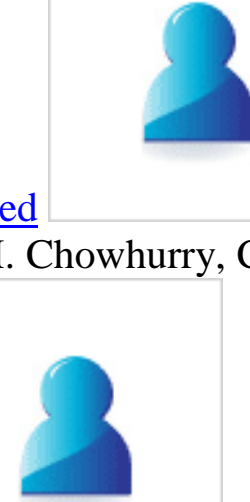
35. J. C. Butcher, Numerical Methods for Ordinary Differential Equations, Wiley,

2003 Search PubMed

36. D. Rehm and A. Weller, Bunsen-Ges. Phys. Chem., Ber., 1969, 73, 834-

839 CAS

37. U. Werner and H. Staerk, J. Phys. Chem., 1995, 99, 248-

256 CrossRef CAS

38. K. Pal, D. R. Kattnig, G. Grampp and S. Landgraf, Phys. Chem. Chem. Phys.,

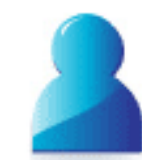

2012, 14, 3155-3161 RSC

39. S. Bandyopadhyay, K. Sen, S. D. Choudhury and S. Basu, RIKEN Rev., 2002,

44, 56-58 CAS

40. S. Richert, A. Rosspeinter, S. Landgraf, G. Grampp, E. Vauthey and D. R. Kattnig, J. Am. Chem. Soc., 2013, 135, 15144- 
41. M. Goez, Pseudo Steady-State Photo-CIDNP measurements, Chem. Phys. Lett.,

1992, 188, 451-456 CrossRef CAS

42. P. A. Purtov and A. B. Doktorov, Chem. Phys., 1993, 178, 47-

65 CrossRef CAS

43. A. Parnachev, P. Purtov, E. Bagryanskaya and R. Sagdeev, J. Chem. Phys.,

1997, 107, 9942-9953 CrossRef CAS

44. J. Moreno, F. Urena and J. Gonzalez, Vib. Spectrosc., 2009, 51, 318

325 CrossRef

45. H. J. Jensen and J. Olsen, Advances in Quantum Chemistry, Academic Press, 1st

edn, 2005 Search PubMed

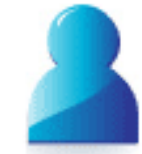

46. A. Baev, M. Samoc, P. N. Prasad, M. Krykunov and J. Autschbach, Opt.

Express, 2007, 15, 5730-5741 CrossRef $\underline{\text { CAS }} \underline{\text { PubMed }}$

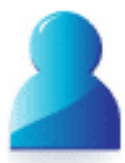


47. J. Moreno, F. Urena and J. Gonzalez, Struct. Chem., 2011, 22, 67-

76 CrossRef CAS

48. M. J. Frisch, G. W. Trucks, H. B. Schlegel, G. E. Scuseria, M. A. Robb, J. R.

Cheeseman, G. Scalmani, V. Barone, B. Mennucci, G. A. Petersson, H.

Nakatsuji, M. Caricato, X. Li, H. P. Hratchian, A. F. Izmaylov, J. Bloino, G.

Zheng, J. L. Sonnenberg, M. Hada, M. Ehara, K. Toyota, R. Fukuda, J.

Hasegawa, M. Ishida, T. Nakajima, Y. Honda, O. Kitao, H. Nakai, T. Vreven, J.

A. Montgomery, Jr., J. E. Peralta, F. Ogliaro, M. Bearpark, J. J. Heyd, E.

Brothers, K. N. Kudin, V. N. Staroverov, R. Kobayashi, J. Normand, K.

Raghavachari, A. Rendell, J. C. Burant, S. S. Iyengar, J. Tomasi, M. Cossi, N.

Rega, J. M. Millam, M. Klene, J. E. Knox, J. B. Cross, V. Bakken, C. Adamo, J. Jaramillo, R. Gomperts, R. E. Stratmann, O. Yazyev, A. J. Austin, R. Cammi, C. Pomelli, J. W. Ochterski, R. L. Martin, K. Morokuma, V. G. Zakrzewski, G. A. Voth, P. Salvador, J. J. Dannenberg, S. Dapprich, A. D. Daniels, Ö. Farkas, J. B. Foresman, J. V. Ortiz, J. Cioslowski and D. J. Fox, Gaussian 09, Revision C.1,

Gaussian, Inc., Wallingford, CT, 2009 Search PubMed

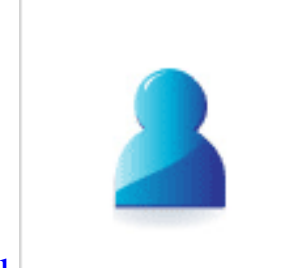

Gaussian, Inc., Walling ford, CT, 2009 Search PubMed

49. A. D. Becke, J. Chem. Phys., 1993, 98, 5648 CrossRef CAS

50. C. Lee, W. Yang and R. G. Parr, Phys. Rev. B: Condens. Matter Mater. Phys.,

1988, 37, 785 CrossRef CAS

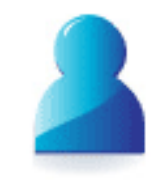

51. W. J. Hehre, R. Ditchfield and J. A. Pople, J. Chem. Phys., 1972, 56, 
52. K. Raghavachari, J. S. Binkley, R. Seeger and J. A. Pople, J. Chem. Phys., 1980,

72, 650 CrossRef

53. J. Tomasi, B. Mennucci and R. Cammi, Chem. Rev., 2005, 105, 2999-

3094 CrossRef CAS PubMed

54. S. Sanoh, A. Horigushi, K. Sugihara, Y. Kotake, Y. Tayama, N. Uromaru, H.

Ohshita, Ch. Tateno, T. Horie, Sh. Kitamura and Sh. Otha, Drug Metab. Dispos.,

2012, 40, 2267-2272 CrossRef CAS PubMed

55. M. El Mouelhi, H. W. Ruelius, C. Fenselau and D. M. Dulik, Drug Metab.

Dispos., 1987, 15, 767-772 $\underline{\text { CAS }}$

\section{Footnote}

$\dagger$ Electronic supplementary information (ESI) available: Description of the applied experimental procedures as well as details on the computational methods and approximations used in the simulation of the CIDNP data. Also, the synthesis details of the studied compounds and their characterization. See DOI: $10.1039 / \mathrm{c} 5 \mathrm{cp} 07305 \mathrm{~g}$

This journal is $@$ the Owner Societies 2016 